\title{
Anti-inflammatory Effects of Ethanolic Extracts from Codium fragile on LPS-Stimulated RAW 264.7 Macrophages via Nuclear Factor kappaB Inactivation
}

\author{
Ho-Dong Yoon ${ }^{1}$, Eun-Ji Jeong ${ }^{2}$, Ji-Woong Choi ${ }^{2}$, Min-Sup Lee ${ }^{2}$, Myoung-Ae Park ${ }^{3}$, Na Young Yoon ${ }^{1}$, \\ Yeon-Kye Kim ${ }^{1}$, Deuk Moon $\mathrm{Cho}^{4}$, Jae-Il Kim ${ }^{2}$ and Hyeung-Rak Kim ${ }^{2 *}$ \\ ${ }^{1}$ Food and Safety Research Division, National Fisheries Research and Development Institute, Busan 619-705, Korea \\ ${ }^{2}$ Department of Food Science and Nutrition, Pukyong National University, Busan 608-737, Korea \\ ${ }^{3}$ Pathology Division, National Fisheries Research and Development Institute, Busan 619-705, Korea \\ ${ }^{4}$ Department of Food and Nutrition, Dong-Pusan College, Busan 612-715, Korea
}

\begin{abstract}
Bacterial lipopolysaccharide (LPS) induces expression of pro-inflammatory cytokines and enzymes producing nitric oxide (NO) and prostaglandins (PGs) in immune cells. This process is mediated by the activation of nuclear factor kappaB (NF- $\kappa \mathrm{B})$. In this study, we investigated the anti-inflammatory characteristics of Codium fragile ethanolic extract (CFE) mediated by the regulation of inducible nitric oxide synthase (iNOS) and cyclooxygenase-2 (COX-2) using LPS-stimulated murine macrophage RAW 264.7 cells. CFE significantly inhibited LPS-induced NO and $\mathrm{PGE}_{2}$ production in a dose-dependent manner and suppressed the expression of iNOS and COX-2 proteins in LPS-stimulated RAW 264.7 cells with no cytotoxicity. Pro-inflammatory cytokines, such as interleukin (IL)-1 $\beta$, IL-6, and tumor necrosis factor- $\alpha$, were significantly reduced by treatment of CFE in LPS-stimulated RAW 264.7 cells. CFE inhibited the promoter activity of (NF)- $\kappa B$ in LPS-stimulated macrophages. Treatment with CFE suppressed translocation of the NF- $\kappa \mathrm{B}$ p65 subunit by preventing proteolytic degradation of inhibitor of $\kappa \mathrm{B}-\alpha$. These results indicate that the CFE-mediated inhibition of $\mathrm{NO}$ and $\mathrm{PGE}_{2}$ production in LPS-stimulated RAW 264.7 cells is mediated through the NF$\kappa \mathrm{B}-$ dependent transcriptional downregulation of iNOS and COX-2, suggesting the potential of CFE as a nutraceutical with antiinflammatory activity.
\end{abstract}

Key words: Codium fragile, Anti-inflammation, iNOS, COX-2, TNF- $\alpha$, IL-1 $\beta$, IL-6

\section{Introduction}

Inflammation is a complex process regulated by a cascade of cytokines, growth factors, nitric oxide (NO), and prostaglandins (PGs) produced by macrophages. Macrophages are key regulators of the immune response to foreign invaders, such as infectious microorganisms, and are activated by exposure to interferon- $\gamma$, pro-inflammatory cytokines, and bacterial lipopolysaccharides (LPSs) (Xie et al., 1993; Zhang and Ghosh, 2000). Activated macrophages play a pivotal role in inflam- matory diseases via excess secretion of cytokines, including tumor necrosis factor (TNF)- $\alpha$, interleukin (IL)- $1 \beta$, IL-6, and other inflammatory mediators such as $\mathrm{NO}$ and $\mathrm{PGE}_{2}$ (Vane et al., 1994; Marks-Konczalik et al., 1998). Excessive production of inflammatory mediators and cytokines is involved in the pathogenesis of chronic diseases, such as atherosclerosis, inflammatory arthritis, and cancer (Libby, 2006; Packard and Libby, 2008; Solinas et al., 2010). Any substances that inhibit
Open Access http://dx.doi.org/10.5657/FAS.2011.0267

This is an Open Access article distributed under the terms of the Creative Commons Attribution Non-Commercial License (http://creativecommons, org/licenses/by-nc/3.0/) which permits unrestricted non-commercial use, distribution, and reproduction in any medium, provided the original work is properly cited. pISSN: 2234-1749 eISSN: 2234-1757
Received 15 September 2011; Revised 13 October 2011; Accepted 10 November 2011

*Corresponding Author

E-mail: hrkim@pknu.ac.kr 
production of these molecules are considered as potential antiinflammatory agents.

Nuclear factor (NF)- $\kappa$ B plays a pivotal role in the early stages of immune and acute phase inflammatory responses, as well as in cell survival (Makarov, 2001; Li and Verma, 2002). $\mathrm{NF}-\kappa \mathrm{B}$ is usually sequestered in the cytoplasm in an inactive form by the inhibitor of $\kappa \mathrm{B}(\mathrm{I} \kappa \mathrm{B})$ family. NF- $\kappa \mathrm{B}$ activation is associated with increased transcription of genes encoding proinflammatory cytokines, adhesion molecules, and enzymes such as inducible nitric oxide synthase (iNOS) and cyclooxygenase-2 (COX-2) (D’Acquisto et al., 1997; Makarov, 2001). Activation of NF- $\kappa \mathrm{B}$ induced by LPS involves phosphoryla-

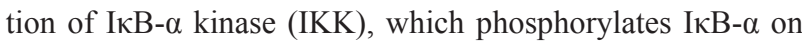
serines 32 and 36 , leading to sequent ubiquitination and degradation of $\mathrm{I} \kappa \mathrm{B}-\alpha$ and translocation of NF- $\kappa \mathrm{B}$ into the nucleus (Chen et al., 1995).

Marine algae have been identified as rich sources of structurally diverse bioactive compounds with great pharmaceutical potential (Abad et al., 2008; Blunt et al., 2010). A variety of biological compounds, including phlorotannins and fucoxanthin, were isolated from marine algae and their biological activities characterized (Kim et al., 2005, 2009; Woo et al., 2009). Codium fragile belongs to Codiales and is widely distributed in the coasts of East Asia, Oceania, and northern Europe. In Korea, C. fragile is a common green seaweed that is used as a culinary item. Furthermore, $C$. fragile has been used as an herbal medicine in China to treat vermifuges, urinary diseases, and dropsy (Tseng and Chang, 1984). Few studies have reported the biological activities of $C$. fragile extracts, including antiangiogenic (Ganesan et al., 2010), immunostimulatory (Lee et al., 2010), and antiviral (Ohta et al., 2009) activities. As part of our ongoing effort to isolate lipophilic compounds with anti-inflammatory activities from marine algae, we detected anti-inflammatory activity in $C$. fragile ethanolic extract (CFE). To our knowledge, no previous study has reported on the anti-inflammatory activity of $C$. fragile and so we investigated the anti-inflammatory activity of CFE and its underlying mechanisms using cultured RAW 264.7 cells. Data suggested that CFE may represent a source of nutraceuticals for prevention or treatment of inflammatory diseases.

\section{Materials and Methods}

\section{Plant material and reagents}

C. fragile was collected along the coast of Busan, Korea, in January 2009, and a voucher specimen was deposited in our laboratory (H.R. Kim). Samples were rinsed in tap water to remove salt and dried in an air dryer (Shilla Ref. Co., Busan, Korea) at $60^{\circ} \mathrm{C}$ for $40 \mathrm{~h}$. A dried sample was ground with a hammer mill and the powder stored at $-20^{\circ} \mathrm{C}$ until used. Antibodies against iNOS, COX-2, poly (ADP-ribose) polymerase (PARP), and actin were purchased from Santa Cruz Biotech- nology (Santa Cruz, CA, USA). Antibodies against NF-кB/ p65, I $\kappa$ B- $\alpha$, and $p-\mathrm{I} \kappa \mathrm{B}-\alpha$ were obtained from Cell Signaling Technology (Danvers, MA, USA). 4',6-Diamidino-2-phenylindole (DAPI) and Alexa Fluor 488-conjugated secondary antibodies were acquired from Invitrogen (Carlsbad, CA, USA). Antibodies against anti-rabbit or mouse secondary horseradish peroxidase were purchased from Santa Cruz Biotechnology.

\section{Preparation of CFE}

Dried powder (100 g) of $C$. fragile was extracted three times with $96 \%(\mathrm{v} / \mathrm{v})$ ethanol for $3 \mathrm{~h}$ at $70^{\circ} \mathrm{C}$. The combined extracts were concentrated using a rotary vacuum evaporator (Eyela, Tokyo, Japan) at $40^{\circ} \mathrm{C}$ and lyophilized. Dried CFE $(9.5 \mathrm{~g})$ was dissolved in dimethyl sulfoxide (DMSO) and further diluted with culture media before use. The final concentration of DMSO in cell culture medium was less than $0.1 \%$.

\section{Cell culture and viability assay}

Murine macrophage RAW 264.7 (ATCC, Rockville, MD, USA) cells were cultured at $37^{\circ} \mathrm{C}$ in Dulbecco's modified Eagle's medium (Gibco, Grand Island, NY, USA) supplemented with $10 \%$ fetal bovine serum, penicillin (100 units $/ \mathrm{mL}$ ), and streptomycin sulfate $(100 \mu \mathrm{g} / \mathrm{mL})$ under a humidified $5 \% \mathrm{CO}_{2}$ atmosphere. Cell viability was determined by 3-(4,5-dimethyl-2-yl)-5-(3-carboxymethoxyphenyl)-2-(4-sulfophenyl)-2Htetrazolium (MTS) assay using a CellTiter $96 \mathrm{AQ}_{\text {ueous }}$ One Solution Cell Proliferation Assay Kit (Promega, Madison, WI, USA) according to the manufacturer's instructions. Cells were inoculated at a density of $1 \times 10^{5}$ cells/well into 96-well plates and cultured at $37^{\circ} \mathrm{C}$ for $24 \mathrm{~h}$. The culture medium was replaced with $200 \mu \mathrm{L}$ of serial dilutions $(0-200 \mu \mathrm{g} / \mathrm{mL})$ of CFE and the cells incubated for $24 \mathrm{~h}$. The culture medium was removed and replaced with $95 \mu \mathrm{L}$ fresh culture medium and 5 $\mu \mathrm{L}$ MTS solution. After $1 \mathrm{~h}$, the absorbance at $490 \mathrm{~nm}$ was measured using a microplate reader (Glomax Multi Detection System, Promega).

\section{Measurement of NO, $\mathrm{PGE}_{2}$, and pro-inflammatory cytokines}

RAW 264.7 cells were placed in a 12-well plate at a density of $1 \times 10^{6}$ cells per well and incubated for $24 \mathrm{~h}$. Cultured cells were treated with vehicle or various CFE concentrations for $1 \mathrm{~h}$, and then stimulated with $1 \mu \mathrm{g} / \mathrm{mL}$ LPS for $24 \mathrm{~h}$. Cultured media were collected after centrifugation at 2,000 $\mathrm{g}$ for $10 \mathrm{~min}$ and stored at $-70^{\circ} \mathrm{C}$ until tested. The nitrite concentration in the cultured media was measured as an indicator of NO production. Culture media $(100 \mu \mathrm{L})$ was mixed with the same volume of Griess reagent $(0.1 \%$ naphtylethylene diamine dihydrochloride and $1 \%$ sulfanilamide in $5 \% \mathrm{H}_{3} \mathrm{PO}_{4}$ ). Absorbance of the mixture at $540 \mathrm{~nm}$ was measured with a microplate reader. Levels of PGE ${ }_{2}$, IL-1 $\beta$, IL-6, and TNF- $\alpha$ 
in cultured media were quantitated by enzyme-linked immunosorbent assay (R\&D Systems, Minneapolis, MN, USA) according to the manufacturer's instructions.

\section{Western immunoblot analysis}

RAW 264.7 cells were incubated with various CFE concentrations for $1 \mathrm{~h}$ and stimulated with LPS $(1 \mu \mathrm{g} / \mathrm{mL})$ for 30 min. CFE-treated or -untreated RAW 264.7 cells were washed twice with cold phosphate-buffered saline (PBS) and lysed with lysis buffer (50 mM Tris-HCl, $\mathrm{pH} 7.5,150 \mathrm{mM} \mathrm{NaCl}$, $1 \%$ Nonidet P-40, 1\% Tween 20, 0.1\% sodium dodecyl sulfate, $50 \mathrm{mM}$ sodium fluoride, $1 \mathrm{mM}$ sodium vanadate, $10 \mu \mathrm{g} /$ $\mathrm{mL}$ leupeptin, and $1 \mathrm{mM}$ phenylmethylsulfonyl fluoride) on ice for $1 \mathrm{~h}$. After centrifugation at $18,000 \mathrm{~g}$ for $10 \mathrm{~min}$, the protein concentrations in supernatants were determined, and aliquots of protein $(40 \mu \mathrm{g})$ were separated by sodium dodecyl sulfate-polyacrylamide gel electrophoresis (SDS-PAGE) and transferred onto a nitrocellulose membrane. The membrane was blocked with 5\% nonfat dried milk in Tris-buffered saline Tween 20 (TBST) for $1 \mathrm{~h}$, followed by incubation for $3 \mathrm{~h}$ with primary antibody in TBST containing 5\% nonfat dried milk. The blots were treated with horseradish peroxidase-conjugated secondary antibody in TBST containing 5\% nonfat dried milk for $1 \mathrm{~h}$, and immune complexes were detected using an ECL detection kit (GE Healthcare Life Sciences, Piscataway, NJ, USA).

\section{Transient transfection and luciferase assay}

Murine NF- $\kappa \mathrm{B}$ promoter/luciferase DNA (1 $\mu \mathrm{g})$ (Stratagene, Santa Clara, CA, USA), along with 20 ng control pRLTK DNA (Promega), was transiently transfected into $2 \times 10^{6}$ RAW 264.7 cells/well in a 12-well plate using Lipofectamine/ Plus reagents (Invitrogen) for $24 \mathrm{~h}$. Thereafter, cells were pretreated with $0-200 \mu \mathrm{g} / \mathrm{mL}$ CFE for $1 \mathrm{~h}$ and stimulated with LPS $(1 \mu \mathrm{g} / \mathrm{mL})$ for $6 \mathrm{~h}$. Each well was washed twice with cold PBS, harvested in $100 \mu \mathrm{L}$ of lysis buffer ( $0.5 \mathrm{mM}$ HEPES, $\mathrm{pH}$ 7.8, $1 \%$ Triton $\mathrm{N}-101,1 \mathrm{mM} \mathrm{CaCl}$, and $1 \mathrm{mM} \mathrm{MgCl}_{2}$ ) and used for assessment of luciferase activity using a Dual Luciferase assay kit (Promega). Luminescence was measured on a top counter microplate scintillation and luminescence counter in single-photon counting mode for $0.1 \mathrm{~min} /$ well, following a 5 min adaptation in the dark. Luciferase activity was normalized to the expression of control pRL-TK.

\section{Preparation of cytosolic and nuclear extracts}

RAW 264.7 cells were treated as described above. After pretreatment with CFE for $1 \mathrm{~h}$ and posttreatment with LPS for 30 min, cells were washed twice with cold PBS and collected with $500 \mu \mathrm{L}$ cold PBS. Cell pellets were resuspended in hypotonic buffer (10 mM HEPES/KOH, $10 \mathrm{mM} \mathrm{KCl,} 2 \mathrm{mM} \mathrm{MgCl}_{2}$, $0.1 \mathrm{mM}$ EDTA, $1 \mathrm{mM}$ DTT, and 0.5 mM PMSF, pH 7.9) and incubated on ice for $15 \mathrm{~min}$. After vortexing for $10 \mathrm{~s}$, homogenates were divided into supernatants (cytoplasmic compartments) and pellets (nuclear components) by centrifugation at $13,000 \mathrm{~g}$ for $10 \mathrm{~min}$. The pellet was gently resuspended in 40 $\mu \mathrm{L}$ complete lysis buffer $(50 \mathrm{mM}$ HEPES/KOH, $50 \mathrm{mM} \mathrm{KCl}$, $1 \mathrm{mM}$ DTT, $300 \mathrm{mM} \mathrm{NaCl}, 0.1 \mathrm{mM}$ EDTA, 10\% glycerol, and $0.5 \mathrm{mM}$ PMSF, $\mathrm{pH}$ 7.9) and centrifuged at 13,000 $\mathrm{g}$ for $20 \mathrm{~min}$ at $4^{\circ} \mathrm{C}$. The supernatant was used as the nuclear extract.

\section{Immunofluorescent analysis}

To analyze nuclear localization of NF- $\mathrm{B}$ in RAW 264.7 cells, cells were maintained on glass coverslips (SPL Lifesciences Co., Gyeonggi-do, Korea) in 24-well plates for 24 h. After stimulation with CFE and/or LPS ( $1 \mu \mathrm{g} / \mathrm{mL})$, cells were fixed in $4.0 \%(\mathrm{w} / \mathrm{v})$ paraformaldehyde in PBS for 15 $\mathrm{min}$ at room temperature, then permeabilized with $0.5 \%(\mathrm{v} / \mathrm{v})$ Triton X-100 in PBS for $10 \mathrm{~min}$. Permeabilized cells were washed with PBS and blocked with $3 \%(\mathrm{w} / \mathrm{v})$ bovine serum albumin (BSA, Sigma Co., St. Louis, MO, USA) in PBS for $30 \mathrm{~min}$. Thereafter, cells were incubated in an anti-NF- $\mathrm{KB} /$ p65 polyclonal antibody diluted in 3\% BSA/PBS for $2 \mathrm{~h}$, rinsed three times for 5 min with PBS, and incubated in Alexa Fluor 488-conjugated secondary antibody diluted in 3\% BSA/PBS for $1 \mathrm{~h}$. Cells were on mounted with $2 \mu \mathrm{g} / \mathrm{mL}$ DAPI and viewed, and images were captured using an LSM700 laser scanning confocal microscope (Carl Zeiss, Oberkochen, Germany).

\section{Statistical analysis}

Data were expressed as the means \pm SDs. Data were analyzed using a one-way analysis of variance (ANOVA), followed by Student's $t$-tests for multiple comparisons. Differences were considered significant at values of $P<0.05$. All analyses were performed using SPSS for Windows, version 10.07 (SPSS Inc., Chicago, IL, USA).

\section{Results}

\section{CFE inhibits NO and $\mathrm{PGE}_{2}$ production in LPS- stimulated cells}

To evaluate the effect of CFE on NO production in LPSstimulated RAW 264.7 cells, we measured nitrite concentrations in culture media using the Griess reagent. RAW 264.7 cells were pretreated with 50-200 $\mu \mathrm{g} / \mathrm{mL}$ CFE for $1 \mathrm{~h}$ and stimulated with LPS for $24 \mathrm{~h}$. NO production, measured as nitrite, was increased by LPS alone; however, CFE significantly reduced NO levels in LPS-stimulated cells in a dose-dependent manner (Fig. 1A). To determine the effect of CFE on $\mathrm{PGE}_{2}$ production in LPS-stimulated RAW 264.7 cells, $\mathrm{PGE}_{2}$ concentrations in culture media were determined by ELISA. 

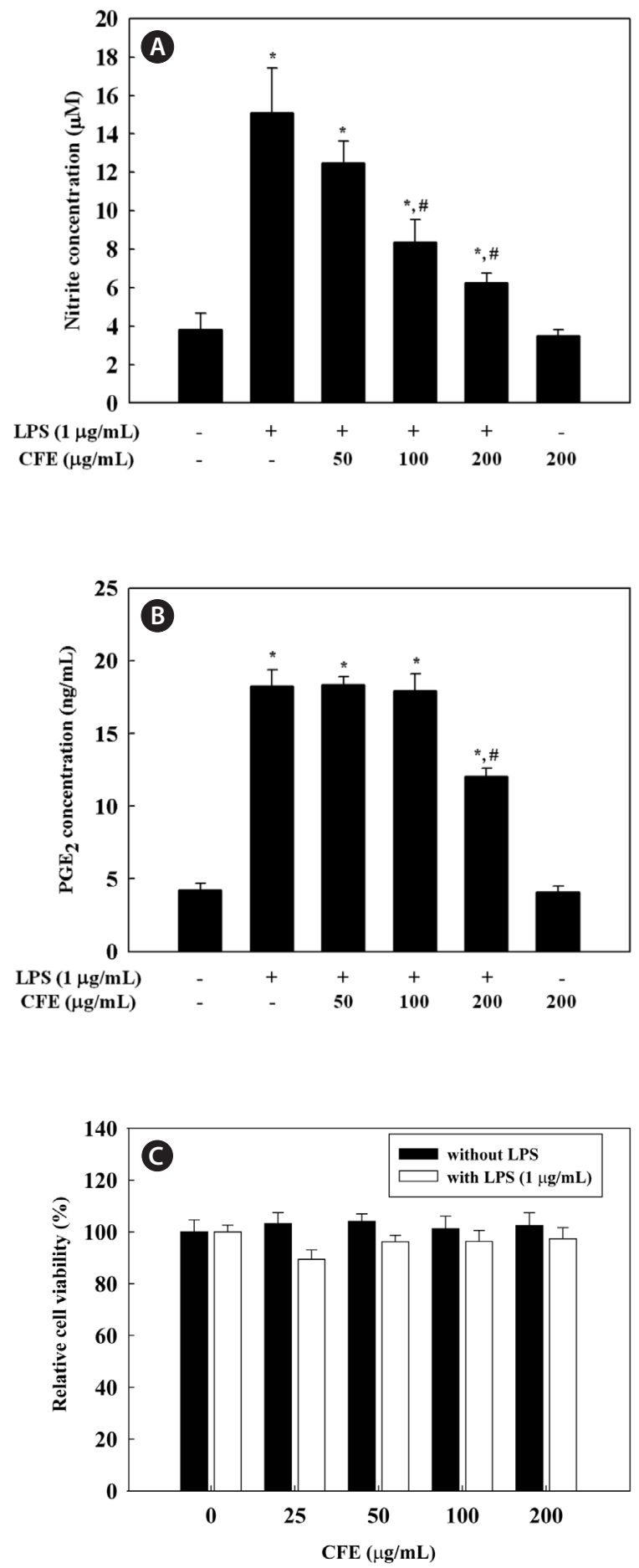

Fig. 1. Effect of Codium fragile ethanolic extract (CFE) on the lipopolysaccharide (LPS)-induced nitric oxide and prostaglandin $E_{2}$ $\left(\mathrm{PGE}_{2}\right)$ production in RAW 264.7 cells. Cells pretreated with different concentrations $(50,100,200 \mu \mathrm{g} / \mathrm{mL}$ ) of CFE for $1 \mathrm{~h}$ were stimulated with LPS $(1 \mu \mathrm{g} / \mathrm{mL})$ for $24 \mathrm{~h}$. The cultured media were used to measure the amount of nitrite to evaluate $\mathrm{NO}$ production $(\mathrm{A})$ and $\mathrm{PGE}_{2}$ production (B). Cytotoxic effect of CFE was measured by MTS assay (C). Values are the means \pm SDs of three independent experiments. ${ }^{*} P<0.05$ indicates significant differences from the control group, ${ }^{\#} P<0.05$ indicates significant differences from the LPS-treated group.

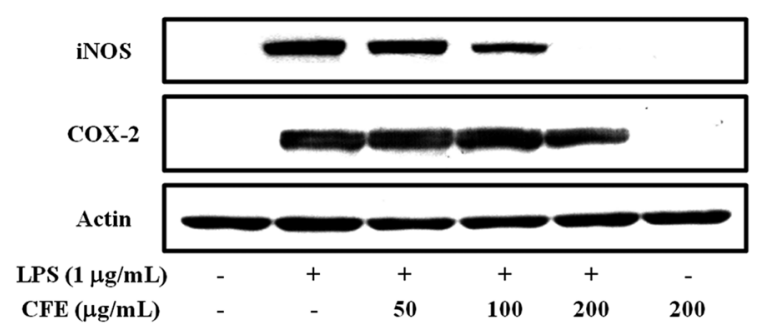

Fig. 2. Effect of Codium fragile ethanolic extract (CFE) on lipopolysaccharide (LPS)-stimulated nitric oxide synthase (iNOS) and cyclooxygenase-2 (COX-2) protein expression in RAW 264.7 cells. Cells pretreated with indicated concentration of CFE for $1 \mathrm{~h}$ were stimulated with LPS $(1 \mu \mathrm{g} / \mathrm{mL})$ for $16 \mathrm{~h}$. Equal amounts of proteins were subjected to $10 \%$ sodium dodecyl sulfate-polyacrylamide gel electrophoresis. The expression of iNOS, COX-2 and actin protein was detected by Western blotting using corresponding antibodies.

$\mathrm{PGE}_{2}$ production by RAW 264.7 cells was increased by LPS treatment, although $200 \mu \mathrm{g} / \mathrm{mL}$ CFE suppressed the production of PGE $_{2}$ in LPS-stimulated RAW 264.7 cells. To exclude the possibility that the decreased $\mathrm{NO}$ and $\mathrm{PGE}_{2}$ levels were due to cell death, we determined the effect of various CFE concentrations on cell viability. The MTS assay demonstrated that CFE showed no cytotoxicity in RAW 264.7 cells up to $200 \mu \mathrm{g} / \mathrm{mL}$ (Fig. 1C). Thus, the inhibitory effects of CFE on $\mathrm{NO}$ and $\mathrm{PGE}_{2}$ production were not due to cytotoxicity. Thus, CFE significantly inhibited $\mathrm{NO}$ and $\mathrm{PGE}_{2}$ production by LPSstimulated RAW 264.7 cells.

\section{CFE inhibits the expression of iNOS and COX-2 in LPS-stimulated cells}

Since iNOS and COX-2 are the key enzymes for the production of $\mathrm{NO}$ and $\mathrm{PGE}_{2}$, respectively, we analyzed the expression iNOS and COX-2 proteins in LPS-stimulated RAW 264.7 cells by Western blotting. As shown in Fig. 2, CFE strongly inhibited the expression of iNOS in a dose-dependent manner; however, inhibition of COX-2 expression occurred at $200 \mu \mathrm{g} / \mathrm{mL}$ CFE, similar to the suppression of $\mathrm{PGE}_{2}$ production (Fig. 1B). These results suggest that the CFE-mediated inhibition of $\mathrm{NO}$ and $\mathrm{PGE}_{2}$ production in LPS-stimulated macrophages is associated with downregulation of iNOS and COX-2 expression.

\section{CFE inhibits production of TNF- $\alpha$, IL-1 $\beta$, and IL- 6 in LPS-stimulated cells}

Since CFE was found to inhibit the expression of NO and $\mathrm{PGE}_{2}$ in a dose-dependent manner, we investigated the effect of CFE on production of pro-inflammatory cytokines by LPSstimulated RAW 264.7 cells, including TNF- $\alpha$, IL-1 $\beta$, and IL- 6 by ELISA. Stimulation of RAW 264.7 cells with LPS led to significantly increased levels of TNF- $\alpha$ (Fig. 3A), IL$1 \beta$ (Fig. 3B), and IL-6 (Fig. 3C). However, pro-inflammatory 

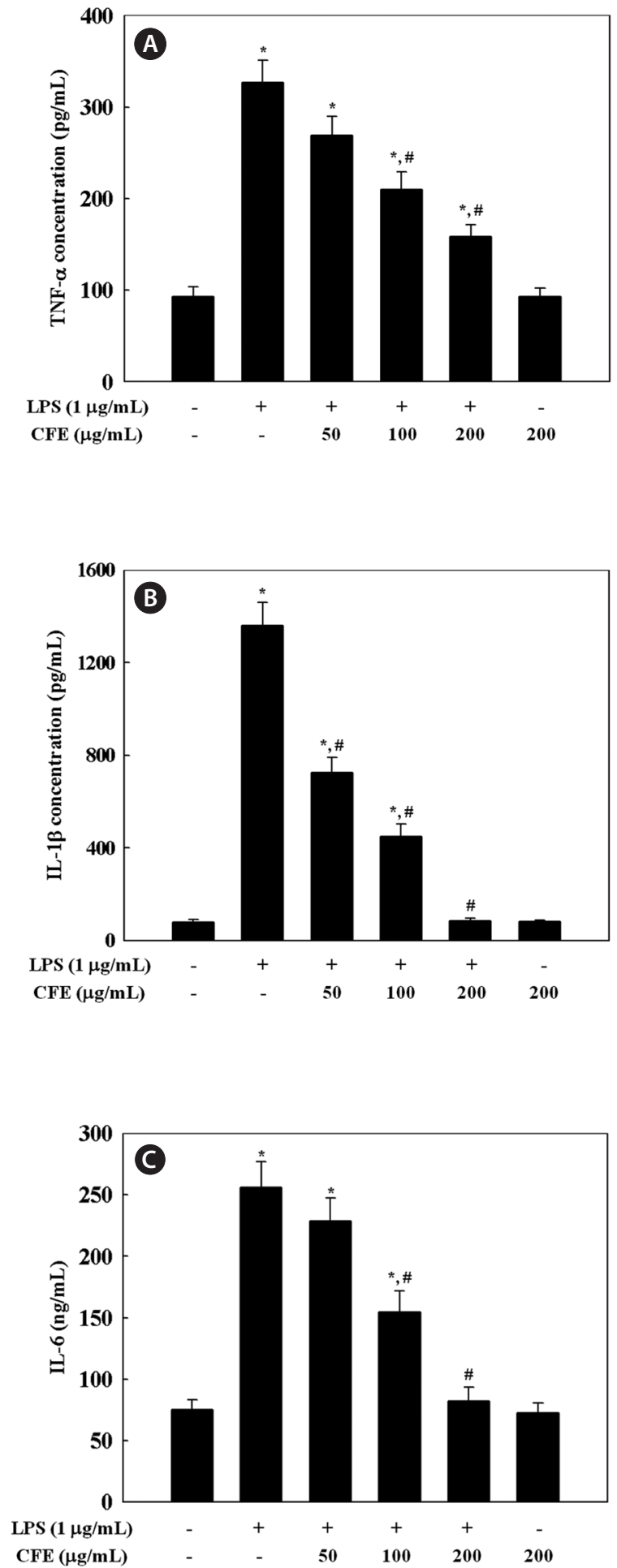

Fig. 3. Effects of Codium fragile ethanolic extract (CFE) on the proinflammatory cytokine productions in RAW 264.7 cells. RAW 264.7 cells pretreated with indicated concentration of CFE for $1 \mathrm{~h}$ were stimulated with lipopolysaccharide (LPS) $(1 \mu \mathrm{g} / \mathrm{mL})$ for $24 \mathrm{~h}$. Tumor necrosis factor (TNF)- $a$ (A), interleukin (IL)-1 1 (B), and IL-6 (C) in the cultured media were measured by enzyme-linked immunosorbent assay. Data are mean \pm SDs. of three independent experiments. ${ }^{*} P<0.05$ indicates significant differences from the control group, ${ }^{\#} P<0.05$ indicates significant differences from the LPStreated group. cytokine production in LPS-stimulated RAW 264.7 cells was inhibited in a dose-dependent manner by exposure to 50-200 $\mu \mathrm{g} / \mathrm{mL}$ CFE (Fig. 3). The inhibitory effect of CFE on TNF- $\alpha$, IL-1 $\beta$, and IL-6 production was not due to cytotoxicity, since cell viability was not altered by CFE at the concentrations used (Fig. 1C). This result indicates that CFE significantly suppressed LPS-induced TNF- $\alpha$, IL- $1 \beta$, and IL- 6 production, which supports the hypothesis that CFE inhibits the initial phase of the LPS-stimulated inflammatory response.

\section{CFE inhibits NF-KB activation in LPS-stimulated RAW 264.7 cells}

We then investigated whether CFE could inhibit the translocation of the NF- $\mathrm{kB} / \mathrm{p} 65$ subunit from the cytosol to the nucleus in LPS-stimulated RAW 264.7 cells. Immunofluorescence revealed that, in unstimulated cells, NF- $\mathrm{kB} / \mathrm{p} 65$ was distributed mostly in the cytoplasm. After stimulation with LPS, most cytoplasmic NF- $\mathrm{kB} / \mathrm{p} 65$ was translocated to the nucleus, as shown by strong NF- $\mathrm{kB} / \mathrm{p} 65$ staining in the nucleus (Fig. $4 \mathrm{~A})$. The level of NF-kB/p65 in the nucleus was markedly reduced by pretreatment with CFE. To assess the molecular mechanisms underlying translocation of NF- $\mathrm{\kappa B}$ from the cytosol to the nucleus in LPS-stimulated RAW 264.7 cells, we also investigated the inhibitory effect of CFE on LPS-stimulated degradation of IKB- $\alpha$, which is responsible for the activation of NF- $\mathrm{KB}$, by Western blotting. LPS treatment resulted in increased IкB- $\alpha$ degradation compared to controls, and CFE pretreatment recovered the level of cytosolic IKB- $\alpha$ in a dosedependent manner (Fig. 4B). As a result of IкB- $\alpha$ degradation, the increased nuclear NF-kB/p65 level after LPS stimulation was reduced by CFE pretreatment in a dose-dependent manner (Fig. 4B). Considering the inhibitory effects of CFE on LPS-induced NF- $\kappa B$ activation, we next determined the effect of CFE on the promoter activity of NF-KB in LPS-stimulated macrophage cells. For this, cells were transiently transfected with luciferase DNA containing murine NF- $\mathrm{BB}$ promoter, and the transfected cells were then pretreated for $1 \mathrm{~h}$ with various CFE concentrations, followed by LPS treatment for $6 \mathrm{~h}$. Data suggested that CFE treatment significantly inhibited LPS-induced NF- $\kappa B$ promoter-driven luciferase expression in macrophages (Fig. 4C). These results indicate that the CFEmediated inhibition of iNOS, COX-2, and pro-inflammatory cytokine expression levels was regulated by the NF-KB pathway in LPS-stimulated macrophages.

\section{Discussion}

We investigated the biological effects of CFE on production of inflammatory mediators in LPS-stimulated RAW 264.7 macrophage cells. To further clarify the molecular mechanisms underlying the effect of CFE, we determined the effects of CFE on the production of NO, PGE 2 , TNF- $\alpha$, IL-1 $\beta$, 

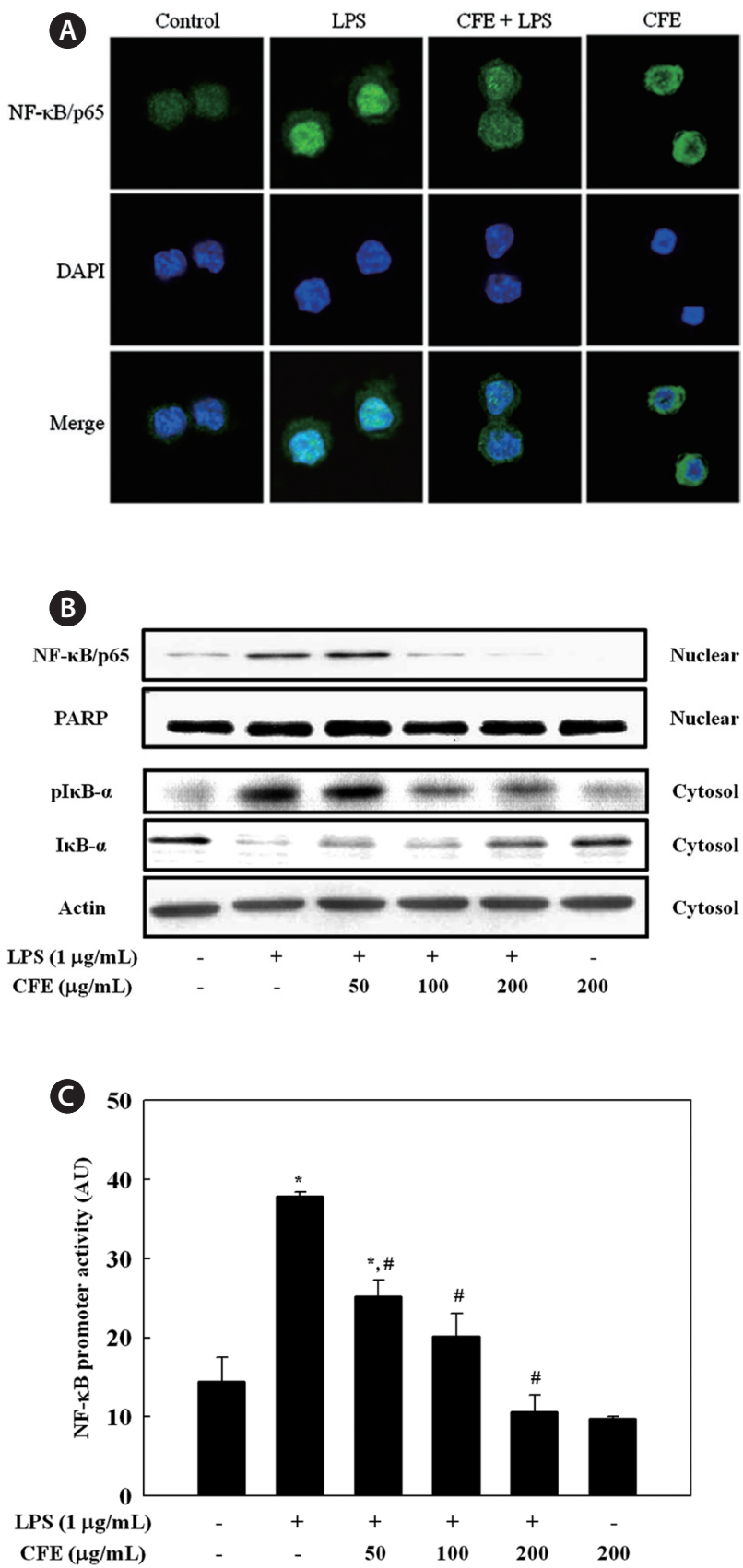

Fig. 4. Effect of Codium fragile ethanolic extract (CFE) on the activation of NF-KB in RAW 264.7 cells. (A) Cells pretreated with CFE $(100 \mu \mathrm{g} / \mathrm{mL})$ for $1 \mathrm{~h}$ were stimulated with $1 \mu \mathrm{g} / \mathrm{mL}$ LPS for $1 \mathrm{~h}$. Cells and nucleus were stained by anti-NF-KB/p65 antibody and DAPI, respectively, and then analyzed using confocal microscopy. The shown results $(\times 100)$ are representative of those obtained in three independent experiments. (B) Cells pretreated with indicated concentration of CFE for $1 \mathrm{~h}$ were stimulated with LPS $(1 \mu \mathrm{g} / \mathrm{mL})$ for $30 \mathrm{~min}$. The phosphorylation of IKB- $\alpha$ and nuclear translocation of NF-KB were determined by Western blotting. (C) Cells were co-transfected with $1 \mu \mathrm{g}$ of NF-KB promotercontaining luciferase DNA along with $20 \mathrm{ng}$ of control pRL-TK DNA for 24 h. Transfected cells were pretreated with various concentration of CFE for $1 \mathrm{~h}$ were stimulated with LPS $(1 \mu \mathrm{g} / \mathrm{mL})$ for $6 \mathrm{~h}$. Data are mean \pm SDs of three independent experiments. $P<0.05$ indicates significant differences from the control group, ${ }^{\#} P<0.05$ indicates significant differences from the LPS-treated group. and IL-6, the expression of iNOS and COX-2 protein, and the activation of NF- $\mathrm{BB}$. Data suggested that CFE effectively inhibited the production of NO, PGE 2 , TNF- $\alpha$, IL- $1 \beta$, and IL-6 through downregulation of NF- $\kappa \mathrm{B}$ activity. The inhibitory effect of CFE on inflammatory mediator expression suggests a mechanism responsible for its anti-inflammatory action and its potential for use as a therapeutic or nutraceutical agent for inflammatory diseases.

$\mathrm{NO}$ is synthesized from L-arginine and molecular oxygen by the action of NOS. Under pathological conditions, a significant increase in NO synthesis by iNOS participates in provoking inflammatory process and acts synergistically with other inflammatory mediators (Nathan, 1992). Also, iNOS is strongly stimulated upon exposure to bacterial endotoxin or pro-inflammatory cytokines (Guha and Mackman, 2001). Compounds capable of reducing NO production or iNOS activity may be attractive as anti-inflammatory agents, and for this reason, the suppressive effects of natural marine compounds on NO production have been intensively studied to develop anti-inflammatory drugs (Abad et al., 2008; Jung et al., 2009; Heo et al., 2010; Jin et al., 2010; Kim and Kim, 2010). COXs regulate the conversion of arachidonic acid to $\mathrm{PGE}_{2}$ and are rate-limiting enzymes in the biosynthesis of PGs. COX-1 is constitutively expressed in many tissues, while COX-2 is an inducible enzyme that produces, in most cases, large quantities of PGs. COX-2 is highly expressed in inflammation-related cell types, including macrophages and mast cells, after stimulation by pro-inflammatory cytokines and/or LPS (Nathan, 1992; Vane et al., 1994). Recent studies have shown that in vivo or in vitro treatment with natural compounds effectively reduces inflammation by suppressing iNOS and COX-2 (Chung et al., 2011; Shin et al., 2010; Pan et al., 2011). These data suggest that CFE-mediated inhibition of $\mathrm{NO}$ and $\mathrm{PGE}_{2}$ production in LPS-stimulated macrophage cells was associated with downregulation of iNOS and COX-2 proteins.

Pro-inflammatory cytokines, such as TNF- $\alpha$, IL- $1 \beta$, and IL6 , are small secreted proteins that regulate immunity and inflammation. Bacterial LPS stimulates macrophages to release TNF- $\alpha$, and the secreted TNF- $\alpha$ or LPS then induces release of IL-1 $\beta$ and IL-6 (Beutler and Cerami, 1989). TNF- $\alpha$ induces several physiological effects, including septic shock, inflammation, and cytotoxicity (Dinarello, 1999). IL-1 $\beta$ is a major pro-inflammatory cytokine that is produced mainly by macrophages and is believed to play a significant role in the pathophysiology of endometriosis (Lebovic et al., 2000). Moreover, IL-1 $\beta$ is important for the initiation and enhancement of the inflammatory response to microbial infection (Kim and Moudgil, 2008). IL-6 is also a pivotal pro-inflammatory cytokine synthesized mainly by macrophages; it plays a role in the acute-phase immune response (Yoshimura, 2006) and is regarded as an endogenous mediator of LPS-induced fever. Our data indicate that CFE significantly suppressed LPSstimulated TNF- $\alpha$, IL-1 $\beta$, and IL-6 secretion, which supports 
the hypothesis that CFE inhibits the initial phase of a LPSstimulated inflammatory response.

The induction of inflammatory mediators, such as NO and $\mathrm{PGE}_{2}$, and pro-inflammatory cytokines, such as TNF- $\alpha$, IL-1 $\beta$, and IL-6, is dependent on NF- $\kappa \mathrm{B}$ activation ( $\mathrm{Li}$ and Verma, 2002). NF- $\kappa$ B plays a pivotal role in the regulation of cell survival genes and coordinates the expression of proinflammatory enzymes and cytokines, such as iNOS, COX-2, TNF- $\alpha$, IL-1 $\beta$, and IL-6 (Xie et al., 1993; D'Acquisto et al., 1997; Marks-Konczalik et al., 1998; Makarov, 2001). NF-кB is associated with an inhibitory subunit, $\mathrm{I} \kappa \mathrm{B}$, which is present in the cytoplasm in an inactive form. Activation of NF- $\mathrm{B}$ induced by LPS or pro-inflammatory cytokines leads to the phosphorylation of IKK, which then phosphorylates I $\mathrm{BB}-\alpha$ on serines 32 and 36, leading to subsequent degradation of IкB- $\alpha$ and inducing translocation of NF- $\mathrm{KB}$ into the nucleus (Chen et al., 1995). In this study, we observed that downregulation of I $\kappa \mathrm{B}-\alpha$ by LPS was recovered by CFE treatment, suggesting that CFE protected the proteolytic degradation of I $\mathrm{B}-\alpha$. Degradation of I $\mathrm{K} \mathrm{B}-\alpha$ involves its dissociation from the inactive complex, leading to activation of NF- $\kappa \mathrm{B}$ in response to LPS. Moreover, using immunofluorescence, we found that nuclear translocation of NF- $\kappa \mathrm{B}$ was significantly inhibited by CFE, supporting the inhibition of I $\mathrm{B}$ - $\alpha$ degradation by CFE. From these data, the CFE-mediated downregulation of LPS-induced iNOS, COX-2, TNF- $\alpha$, IL-1 $\beta$, and IL-6 expression in RAW 264.7 cells is most likely largely associated with the ability of CFE to inhibit the NF- $\mathrm{KB}$ pathway. This is, to our knowledge, the first report addressing the negative regulation by CFE of the NF- $\kappa \mathrm{B}$ pathway in response to LPS.

In conclusion, we demonstrated that CFE inhibited the production of inflammatory mediators, such as $\mathrm{NO}$ and $\mathrm{PGE}_{2}$, and pro-inflammatory cytokines, including TNF- $\alpha$, IL- $1 \beta$, and IL6, in LPS-stimulated RAW 264.7 macrophages. Moreover, the inhibitory effect of CFE was associated with inactivation of the $\mathrm{NF}-\kappa \mathrm{B}$ pathway via blocking $\mathrm{I} \kappa \mathrm{B}$ degradation. Confirmation of the anti-inflammatory activity of CFE and the mechanism underlying its effects contributes to the further application of CFE in functional food for inflammation-mediated diseases. These results suggest to us additional studies with the aim of determining the compound(s) within CFE that contribute to its anti-inflammatory activity.

\section{Acknowledgments}

This work was financially supported by the National Fisheries Research and Development Institute (RP-2011-BT-61) and Brain Busan 21.

\section{References}

Abad MJ, Bedoya LM and Bermejo P. 2008. Natural marine anti-inflam- matory products. Mini Rev Med Chem 8, 740-754.

Beutler B and Cerami A. 1989. The biology of cachectin/TNF--a primary mediator of the host response. Annu Rev Immunol 7, 625-655.

Blunt JW, Copp BR, Munro MH, Northcote PT and Prinsep MR. 2010. Marine natural products. Nat Prod Rep 27, 165-237.

Chen Z, Hagler J, Palombella VJ, Melandri F, Scherer D, Ballard D and Maniatis T. 1995. Signal-induced site-specific phosphorylation targets IкB $\alpha$ to the ubiquitin-proteasome pathway. Genes Dev 9, 1586-1597.

Chung EY, Kim BH, Hong JT, Lee CK, Ahn B, Nam SY, Han SB and Kim Y. 2011. Resveratrol down-regulates interferon- $\gamma$-inducible inflammatory genes in macrophages: molecular mechanism via decreased STAT-1 activation. J Nutr Biochem 22, 902-909.

D'Acquisto F, Iuvone T, Rombolà L, Sautebin L, Di Rosa M and Carnuccio R. 1997. Involvement of NF- $\mathrm{kB}$ in the regulation of cyclooxygenase-2 protein expression in LPS-stimulated J774 macrophages. FEBS Lett 418, 175-178.

Dinarello CA. 1999. Cytokines as endogenous pyrogens. J Infect Dis 179(Suppl 2), S294-S304.

Ganesan P, Matsubara K, Ohkubo T, Tanaka Y, Noda K, Sugawara T and Hirata T. 2010. Anti-angiogenic effect of siphonaxanthin from green alga, Codium fragile. Phytomedicine 17, 1140-1144.

Guha M and Mackman N. 2001. LPS induction of gene expression in human monocytes. Cell Signal 13, 85-94.

Heo SJ, Yoon WJ, Kim KN, Ahn GN, Kang SM, Kang DH, Affan A, Oh C, Jung WK and Jeon YJ. 2010. Evaluation of anti-inflammatory effect of fucoxanthin isolated from brown algae in lipopolysaccharide-stimulated RAW 264.7 macrophages. Food Chem Toxicol 48, 2045-2051.

Jin M, Suh SJ, Yang JH, Lu Y, Kim SJ, Kwon S, Jo TH, Kim JW, Park YI, Ahn GW, Lee CK, Kim CH, Son JK, Son KH and Chang HW. 2010. Anti-inflammatory activity of bark of Dioscorea batatas DECNE through the inhibition of iNOS and COX-2 expressions in RAW264.7 cells via NF-kB and ERK1/2 inactivation. Food Chem Toxicol 48, 3073-3079.

Jung WK, Ahn YW, Lee SH, Choi YH, Kim SK, Yea SS, Choi I, Park SG, Seo SK, Lee SW and Choi IW. 2009. Ecklonia cava ethanolic extracts inhibit lipopolysaccharide-induced cyclooxygenase-2 and inducible nitric oxide synthase expression in BV2 microglia via the MAP kinase and NF-kB pathways. Food Chem Toxicol 47:410417.

Kim AR, Shin TS, Lee MS, Park JY, Park KE, Yoon NY, Kim JS, Choi JS, Jang BC, Byun DS, Park NK and Kim HR. 2009. Isolation and identification of phlorotannins from Ecklonia stolonifera with antioxidant and anti-inflammatory properties. J Agric Food Chem 57, 3483-3489.

Kim EY and Moudgil KD. 2008. Regulation of autoimmune inflammation by pro-inflammatory cytokines. Immunol Lett 120, 1-5.

Kim MM and Kim SK. 2010. Effect of phloroglucinol on oxidative stress and inflammation. Food Chem Toxicol 48, 2925-2933.

Kim YC, An RB, Yoon NY, Nam TJ and Choi JS. 2005. Hepatoprotective constituents of the edible brown alga Ecklonia stolonifera on tacrine-induced cytotoxicity in Hep G2 cells. Arch Pharm Res 28, 1376-1380. 
Lebovic DI, Bentzien F, Chao VA, Garrett EN, Meng YG and Taylor RN. 2000. Taylor RN. 2000. Induction of an angiogenic phenotype in endometriotic stromal cell cultures by interleukin-1 $\beta$. Mol Hum Reprod 6, 269-275.

Lee JB, Ohta Y, Hayashi K and Hayashi T. 2010. Immunostimulating effects of a sulfated galactan from Codium fragile. Carbohydr Res $345,1452-1454$

Li Q and Verma IM. 2002. NF- $\kappa B$ regulation in the immune system. Nat Rev Immunol 2, 725-734

Libby P. 2006. Inflammation and cardiovascular disease mechanisms. Am J Clin Nutr 83, 456S-460S.

Makarov SS. 2001. NF- $\mathrm{kB}$ in rheumatoid arthritis: a pivotal regulator of inflammation, hyperplasia, and tissue destruction. Arthritis Res 3, 200-206.

Marks-Konczalik J, Chu SC and Moss J. 1998. Cytokine-mediated transcriptional induction of the human inducible nitric oxide synthase gene requires both activator protein 1 and nuclear factor $\mathrm{\kappa B}$ binding sites. J Biol Chem 273, 22201-22208.

Nathan C. 1992. Nitric oxide as a secretory product of mammalian cells. FASEB J 6, 3051-3064.

Ohta Y, Lee JB, Hayashi K and Hayashi T. 2009. Isolation of sulfated galactan from Codium fragile and its antiviral effect. Biol Pharm Bull 32, 892-898.

Packard RR and Libby P. 2008. Inflammation in atherosclerosis: from vascular biology to biomarker discovery and risk prediction. Clin Chem 54, 24-38.

Pan MH, Hong HM, Lin CL, Jhang AZ, Tsai JH, Badmaev V, Nagabhushanam K, Ho CT and Chen WJ. 2011. Se-methylselenocysteine inhibits lipopolysaccharide-induced NF- $\mathrm{KB}$ activation and iNOS induction in RAW 264.7 murine macrophages. Mol Nutr Food Res
$55,723-732$

Shin JS, Park YM, Choi JH, Park HJ, Shin MC, Lee YS and Lee KT. 2010. Sulfuretin isolated from heartwood of Rhus verniciflua inhibits LPS-induced inducible nitric oxide synthase, cyclooxygenase-2, and pro-inflammatory cytokines expression via the downregulation of NF-kB in RAW 264.7 murine macrophage cells. Int Immunopharmacol 10, 943-950.

Solinas G, Marchesi F, Garlanda C, Mantovani A and Allavena P. 2010. Inflammation-mediated promotion of invasion and metastasis. Cancer Metastasis Rev 29, 243-248.

Tseng CK and Chang CF. 1984. Chienese seaweeds in herbal medicine. Hydrobiologia 116/117, 152-154.

Vane JR, Mitchell JA, Appleton I, Tomlinson A, Bishop-Bailey D, Croxtall J and Willoughby DA. 1994. Inducible isoforms of cyclooxygenase and nitric-oxide synthase in inflammation. Proc Natl Acad Sci U S A 91, 2046-2050.

Woo MN, Jeon SM, Shin YC, Lee MK, Kang MA and Choi MS. 2009. Anti-obese property of fucoxanthin is partly mediated by altering lipid-regulating enzymes and uncoupling proteins of visceral adipose tissue in mice. Mol Nutr Food Res 53, 1603-1611.

Xie QW, Whisnant R and Nathan C. 1993. Promoter of the mouse gene encoding calcium-independent nitric oxide synthase confers inducibility by interferon $\gamma$ and bacterial lipopolysaccharide. J Exp Med $177,1779-1784$

Yoshimura A. 2006. Signal transduction of inflammatory cytokines and tumor development. Cancer Sci 97, 439-447.

Zhang G and Ghosh S. 2000. Molecular mechanisms of NF-kB activation induced by bacterial lipopolysaccharide through Toll-like receptors. J Endotoxin Res 6, 453-457. 